\title{
ANÁLSE DE GÊNEROS DISCURSIVOS NA ESFERA PEDAGÓGICA: A PROVA DISCURSIVA DE ĹNGUA PORTUGUESA NO VESTIBULAR
}

Erislane Rodrigues Ribeiro ${ }^{1}$

Resumo: Por considerarmos bastante relevante os estudos de gêneros discursivos na esfera pedagógica como forma de embasar as práticas de escrita e leitura realizadas nas escolas, com este artigo pretendemos dar nossa contribuição, analisando o gênero prova discursiva de Língua Portuguesa. Procuraremos observar, em prova de Língua Portuguesa do Processo Seletivo 2004 da UFG, como se configura seu conteúdo temático, sua forma composicional e seu estilo, conforme a teoria proposta por Bakhtin.

Palavras-Chave: Gêneros do discurso, prova discursiva, Língua Portuguesa, vestibular.

Abstract: Through this article, we intend to give our contribution to genre discursive test of Portuguese because we consider very important for the study of genres of the pedagogic sphere as a way of teaching based practices of reading and writing carried out in schools. We intend to observe in tests of Portuguese of the Selective Process 2004 of UFG, as set their thematic content, its form and its composicional style, as the theory proposed by Bakhtin.

Key Words: Discursive genres, discursive test, Portuguese, vestibular.

\section{INTRODUÇÃO}

A escola é uma importante esfera de atividade de nossa sociedade e como tal tem seus próprios gêneros discursivos, por intermédio dos quais se constituem e se desenvolvem as diversas interações escolares e/ ou as atividades de ensino e de aprendizagem.

Na opinião de Rodrigues (2002, p. 213), "o sucesso do aluno na escola passa pelo domínio dos gêneros escolares, que também devem ser considerados objetos de aprendizagem". Para ela, "um projeto pedagógico para a produção da escrita", além de contribuir "para a plena participação na vida social pública", deve se orientar "(sem excluir os demais) para aqueles gêneros cujo domínio é necessário para o bom desempenho escolar (saber tomar notas, fazer resumos, resenhas, participar de seminários, etc.)".

Em consonância com o que defende a autora, ressaltamos a importância de se exercitar, nas aulas de língua portuguesa, a leitura e escrita de provas discursivas de concursos e vestibulares para que, conhecendo as especificidades desse gênero, os indivíduos se saiam melhor no momento em que com eles se defrontam.

1 Doutora em Lingüística e Língua Portuguesa pela FCLAR/UNESP; Docente do Curso de Letras, Campus Catalão, Universidade Federal de Goiás; endereço eletrônico: erislane@bol.com.br. 
Nosso objetivo, com a escrita deste artigo, é, então, desenvolver a análise do gênero prova discursiva de Língua Portuguesa em contexto de vestibular, pois sabemos que, como afirma Rocco (1995, p. 24), as características da nossa realidade escolar, sobretudo a de $2 \circ$ grau, não nos permite negar ou mesmo "desconhecer 0 alto nível de influência que 0 vestibular exerce sobre 0 ensino". Desta forma, com base na teoria bakhtiniana, procuramos observar como a prova discursiva de Língua Portuguesa do Processo Seletivo de $2004^{2}$ se caracteriza em termos de forma composicional, conteúdo temático e estilo.

0 presente texto encontra-se organizado do seguinte modo. Inicialmente, apresentamos algumas considerações sobre: 0 que vem a ser gêneros do discurso segundo propõe Bakhtin, como eles podem ser distinguidos dos tipos, a intrínseca relação que estabelecem com seu suporte, além da reconhecida importância que o trabalho com os gêneros no ensino adquiriu recentemente. A seguir, teorizamos, rapidamente, sobre o gênero prova discursiva de Língua Portuguesa especificamente. Em seguida, analisamos a prova discursiva de Língua Portuguesa do Processo Seletivo 2004 da UFG, observando, especialmente, como ela se constitui no que se refere a seu conteúdo temático, sua forma composicional e seu estilo. Por fim, apresentamos nossas consideraç̧ões finais e as referências bibliográficas.

\section{GÊNEROS DO DISCURSO}

Releituras da obra de Bakhtin já foram realizadas, em outros momentos da história, para reavivar uma série de conceitos, como dialogismo, polifonia, carnavalização, interação. Atualmente, um número bastante significativo dos pesquisadores que cita Bakhtin o faz, principalmente, para abordar o tema gêneros do discurso. No entanto, apesar do número de citações de Bakhtin (2000) em pesquisas que versam sobre a questão dos gêneros, os trabalhos sobre o tema têm se diversificado numa velocidade espantosa, distanciando-se uns dos outros em razão das diferentes leituras dos textos do autor e dos distintos objetivos almejados pelos pesquisadores.

Partindo da idéia defendida por Bakhtin (2000) de que não é possível a comunicação verbal a não ser por algum gênero, vários pesquisadores, dentre eles Marcuschi (2002a) e (2002b), têm procurado mostrar a funcionalidade da noção "gêneros textuais" e defendido a importância de se trabalhar com eles e não com os tipos textuais nas aulas de língua materna. Para M arcuschi (2002a, p. 22), os tipos textuais "abrangem cerca de meia dúzia de categorias conhecidas como: narração, argumentação, exposição, descrição, injunção" e os gêne-

2 As questões desta prova encontram-se em anexo. 
ros são "os textos materializados que encontramos em nossa vida diária e que apresentam características sócio-comunicativas definidas por conteúdos, propriedades funcionais, estilo e composição característica". Em Bakhtin, gênero (às vezes denominado pelo autor de tipos, formas) não são aquelas categorias de que fala Marcuschi (2002, p. 22), mas as formas que os enunciados adquirem em determinadas esferas de atividades entre interlocutores que as reconhecem porque as mesmas se constituíram historicamente, através de processos de interação.

Para Bakhtin (2000, p. 284), gênero do discurso é um “tipo de enunciado, relativamente estável do ponto de vista temático, composicional e estilístico", elaborado por cada esfera em que a língua é utilizada. Conceituando gêneros do discurso em relação às esferas de atividade humana, Bakhtin reconhece que inexistem classificações que partam da observação das esferas da atividade humana, provavelmente em razão de serem tão variadas, fazendo com que os gêneros, por sua vez, sejam também variados e heterogêneos, de natureza infinita. Para o autor russo, além de inexistir tal classificação, falta estabelecer uma distinção básica entre dois subgrupos de gênero. Num primeiro grupo, incluem-se os gêneros de discurso primários, simples, os quais são constituídos de uma comunicação verbal espontânea; num segundo grupo, estão os gêneros de discurso secundários, complexos, que "aparecem em circunstâncias de uma comunicação cultural mais complexa e relativamente mais evoluída, principalmente escrita: artística, científica, sociopolítica", absorvendo e transformando os gêneros primários (BAKHTIN, 2000, p. 281). Além disso, os gêneros secundários, em sua maior parte, promovem uma "[...] compreensão responsiva de ação retardada: cedo ou tarde, o que foi ouvido e compreendido de modo ativo encontrará um eco no discurso ou no comportamento subseqüente do ouvinte" (BAKHTIN, 2000, p. 291).

A escolha de um gênero do discurso, seja ele primário ou secundário, é, segundo Bakhtin (2000, p. 301), decorrente das especificidades de determinada esfera da comunicação verbal, o que significa dizer que existem gêneros, mais ou menos apropriados, tanto em relação às esferas do cotidiano (familiar, íntima, comunitária) como também em relação às esferas dos sistemas ideológicos constituídos (científica, artística, religiosa, política, jornalística, militar, escolar), aos quais corresponde certo estilo lingüístico ou funcional.

Quanto aos nomes que usamos para designar os gêneros, não são inventados por nós como resultado de um trabalho individual, são constituídos socialmente e historicamente. E em relação aos critérios utilizados no processo de designação dos gêneros, em geral utiliza-se um desses critérios: "forma estrutural, propósito comunicativo, conteúdo, meio de transmissão (suporte), pa- 
péis dos interlocutores, contexto situacional, mas vários desses critérios podem atuar em conjunto" (M ARCUSCHI, 2002b, p. 8).

Uma tese que M arcuschi (2003) tem defendido em relação ao gênero diz respeito à sua estreita relação com o suporte. Definindo o suporte como "um lócus físico com formato específico que serve de base ou ambiente de fixação do gênero materializado como texto", o autor tem apostado na idéia de que "[...] como o suporte tem um formato específico, ele pode ter contribuições ao gênero. [...]. Seria interessante analisar a hipótese de que os gêneros têm preferência e não se manifestam na indiferença a suportes". Em outras palavras, 0 autor atribui grande importância ao suporte para a circulação dos gêneros na sociedade, além de destacar a influência que ele, certamente, acarreta na "natureza do gênero suportado". Desse modo, na visão do autor, "[...] o suporte não é neutro e o gênero não fica indiferente a ele" (M ARCUSCHI, 2003, p. 1-7).

Em relação à aquisição dos gêneros, conforme Bakhtin (2000, p. 301), não se distancia da aprendizagem das formas de nossa língua materna. Para ele, "as formas da língua e as formas típicas de enunciados, isto é, os gêneros do discurso, introduzem-se em nossa experiência e em nossa consciência conjuntamente e sem que sua estreita correlação seja rompida". E como a aprendizagem das formas da língua e dos gêneros do discurso ocorre conjuntamente através de nossas experiências, falta domínio do gênero se há "falta de vivência de determinadas atividades de certa esfera" (FIORIN, 2006, p. 69).

No Brasil, o recente interesse pelo estudo dos gêneros do discurso decorre, em parte, da importância que o M EC tem atribuído ao trabalho com os gêneros no ensino de leitura e produção de textos, em especial nas aulas de língua portuguesa, como se pode verificar pela leitura dos PCNs de língua portuguesa elaborados por esse órgão do governo. De acordo com os PCNs (1997), nas situações de ensino, é necessário contemplar

a diversidade de textos e gêneros, e não apenas em função de sua relevância social, mas também pelo fato de que textos pertencentes a diferentes gêneros são organizados de diferentes formas. A compreensão oral e escrita, bem como a produção oral e escrita de textos pertencentes a diversos gêneros, supõem o desenvolvimento de diversas capacidades que devem ser enfocadas nas situações de ensino. É preciso abandonar a crença na existência de um gênero prototípico que permitiria ensinar todos os gêneros em circulação social (BRASIL, 1997, p. 23-24).

Atualmente, podemos dizer que é quase unânime a opinião de que é necessário trabalhar com a diversidade de gêneros, já que, como ponderou Bakhtin (2000, p. 303), "são muitas as pessoas, que dominando magnificamente a língua, sentem-se logo desamparadas em certas esferas da comunicação ver- 
bal, precisamente pelo fato de não dominarem, na prática, as formas do gênero de uma dada esfera".

\title{
20 GÊNERO PROVA DISCURSIVA
}

\begin{abstract}
Uma prova "discursiva" é, segundo Chociay,
[...] um diálogo regido por um objetivo específico: o professor emite frases com intenção de avaliar; 0 aluno emite frases correspondentes com intenção de ser avaliado. 0 professor quer saber se 0 aluno domina certos conteúdos e alcança certos comportamentos; 0 aluno quer demonstrar que conhece tais conteúdos e exerce tais comportamentos (CHOCIAY, 1998, p. 52).
\end{abstract}

0 modo como Chociay define a prova de vestibular comumente denominada discursiva, sugere-nos que é possível pensar a interlocução entre candidatos e banca a partir das considerações de Pêcheux (1993) quando trata do jogo de imagens que envolve os sujeitos. Geraldi (1993, p. 69-71) propôs um exemplo de como essas imagens funcionam, elaborando "um quadro hipotético de respostas que um aluno, na escola, construiria [...] quando lhe é solicitado que escreva um texto". A partir do quadro proposto pelo autor, desenvolvemos um para compreendermos melhor as imagens envolvidas no processo de interlocução envolvendo banca e vestibulandos no processo seletivo 2004 da UFG.

À pergunta "quem sou eu para lhe falar assim?", é provável que os membros da banca respondessem que são: professores de português, com experiência nos níveis superior e fundamental e/ ou médio, com condições de selecionar, com base no que se ensina nos níveis que antecedem o vestibular, os alunos com condições de ingressar na universidade; pesquisadores atualizados em suas áreas de atuação quanto às mais recentes abordagens teóricas; profissionais que têm, em decorrência de sua formação e profissão, domínio da língua padrão, além de uma competência inquestionável em atividades de avaliação da leitura e escrita de terceiros. Além disso, são pessoas bem informadas, cujos pontos de vista costumam ser considerados relevantes pela sociedade.

À pergunta "quem é ele para eu Ihe falar assim?", a banca, provavelmente, responde que ele é um candidato, alguém que concluiu o ensino fundamental e o ensino médio e que ao candidatar-se a uma vaga na universidade deve demonstrar certos conhecimentos e habilidades e que não pode, ao responder questões da prova de língua portuguesa, cometer erros (nem no conteúdo nem na forma). 
Neste ponto, consideramos pertinente citar Bakhtin (2000, p. 320), para quem,

o enunciado, desde 0 início, elabora-se em função da eventual reação-resposta, a qual é o objetivo preciso de sua elaboração. 0 papel dos outros, para os quais o enunciado se elabora, [...] é muito importante. Os outros, para os quais meu pensamento se torna, pela primeira vez, um pensamento real (e, com isso, real para mim), não são ouvintes passivos, mas participantes ativos da comunicação verbal. Logo de início, o locutor espera deles uma resposta, uma compreensão responsiva ativa. Todo enunciado se elabora como que para ir ao encontro dessa resposta (BAKHTIN, 2000, p. 320).

Quanto à questão, "de que lhe falo eu (banca)?", os professores que compõem a banca responderiam que falam sobre temas relativos à língua portuguesa, pois a prova é de língua portuguesa, além de temas atuais, para avaliar o que 0 aluno tem lido e/ ou se é uma pessoa bem informada. Com base no que propõe o manual do candidato e a partir das abordagens teóricas que se destacam na academia, a banca elabora o seu dizer, tentando evitar, entretanto, que as respostas possam vir a ser muito heterogêneas entre si, o que impossibilitaria a correção.

As imagens que a banca tem de si, dos candidatos que respondem as questões da prova discursiva de língua portuguesa e dos temas nela contidos compõem, portanto, um quadro que, em nossa opinião, pode revelar bastante das condições em que os discursos das bancas são produzidos.

Segundo Chociay, servem de instrumento para o diálogo, para essa relação de interação verbal entre o professor (banca) e 0 aluno (candidato), os "[...] mesmos tipos de frase empregados na comunicação ordinária submetidos, porém, a um processo de elaboração cuidadoso" (CHOCIAY, 1998, p. 52). Ao analisar questões de provas discursivas da Vunesp, 0 autor verifica que:

os enunciados das perguntas desenvolvem-se em dois itens que podem ser denominados, respectivamente, comentário e solicitação. Por meio do comentário são fornecidos ao candidato esclarecimentos sobre o aspecto ou o pormenor do texto focalizado; por meio da solicitação se formula a pergunta propriamente dita, dividida em dois subitens (CHOCIAY, 1998, p. 61).

A vantagem desse tipo de questão é, segundo ele, que o comentário acaba por criar para o candidato "um contexto a partir do qual sua capacidade de observação, análise e interpretação poderá operar-se sem maiores entraves [...]", o que procuraremos observar no momento das análises (CHOCIAY, 1998, p. 63).

No tópico seguinte, passamos a analisar questões da prova discursiva de língua portuguesa propostas pelo centro de seleção da UFG no processo seletivo 2004. 


\section{ANÁLISE DA PROVA DISCURSIVA DE LÍNGUA PORTUGUESA DO PROCESSO SELETIVO 2004 DA UFG}

Em 2004, a segunda etapa do processo seletivo se realizou em dois dias. No primeiro dia, os candidatos receberam o caderno de questões ${ }^{3}$ contendo as questões discursivas de língua portuguesa e aquelas relacionadas às obras literárias previamente indicadas para o vestibular 2004, as quais compõem 0 que a UFG denomina prova de "língua portuguesa". Além dessas questões, no mesmo dia foi realizada a prova de "redação".

A questão 01 dessa prova situa-se no início da página 01 do caderno de questões e inicia-se com uma seqüência injuntiva, pois o objetivo é fazer com que o interlocutor aja, lendo uma nota de Elio Gaspari, retirada da Folha de São Paulo (16 nov. 2003). Como se pode ver, o comentário da questão 01 é caracterizado por uma instrução dada ao vestibulando; pela apresentação da nota irônica de Elio Gaspari, seguida da referência que indica que foi publicada anteriormente pela Folha de São Paulo; por uma contextualização dada através da explicação de quem é M adame Natasha (personagem criada pelo autor para ridicularizar a linguagem usada por autoridades que atropelam a comunicação). Já a solicitação é dividida em perguntas: a, em que se pede ao candidato que explique por que o emprego dos termos "eficientização" e "eficientizados" está sendo criticado, e b, em que se solicita ao vestibulando reescrever 0 último parágrafo conforme a norma padrão.

Em relação à pergunta a, podemos dizer que o comentário feito antes da solicitação, com o uso do texto de Gaspari, seguido da explicação de quem é madame Natasha, delimita as possibilidades de leitura, com a finalidade de direcionar a resposta do vestibulando. Em se tratando de um processo seletivo, tal expediente não merece ser alvo de críticas. Assim, com essa pergunta, pode ser avaliada a capacidade do candidato em identificar pistas no texto que o levam a determinadas leituras.

Como respostas esperadas para a letra a dessa primeira questão, o centro de seleção da UFG divulgou as seguintes"

a) O emprego dos termos "eficientização" e "eficientizados" é criticado por ser uma impropriedade vocabular. Podem ser considerados neo-

3 O "Caderno de questões" é o suporte utilizado pela UFG para as questões das provas e para as respostas dadas pelos candidatos.

4 Em 2004, o Centro de Seleção tornou públicas, em seu site, as respostas esperadas na prova discursiva de língua portuguesa. 
logismos técnicos, usados em lugar de termos disponíveis e recorrentes, tais como "qualificação" e "melhoria". Além de serem questionáveis diante da norma padrão, esses termos manifestam um exagero do estilo técnico e burocrático que não contribui para a clareza da mensagem e que não é, portanto, adequado a textos oficiais nem a autoridades governamentais.

A crítica decorre do fato de um secretário de Estado, Wagner G. Victer, derivar indevidamente os termos "eficientização" e "eficientizados" da palavra "eficiente", pois já existem palavras equivalentes em português, e esses neologismos não contribuem para a clareza do que está sendo comunicado.

Quanto à pergunta $b$ dessa primeira questão, a despeito de tematizar os níveis de linguagem, assunto que merece de fato estar presente em questões de vestibular, valoriza, como em geral acontece nesse tipo de questão, a norma padrão da língua portuguesa.

A segunda questão, apresentada na mesma página da primeira, também é composta por um comentário e pela solicitação, esta dividida em dois itens. Novamente, o comentário se inicia com instruções dirigidas aos candidatos com o fim de desencadear a ação de ler a resenha que se segue e a ação de escrever para responder ao que se pede; a seguir, insere-se uma resenha do filme 0 amor custa caro, adaptada da revista Carta Capital de 15 de outubro de 2003; por último, são apresentadas duas perguntas que devem ser respondidas pelos candidatos.

$\mathrm{Na}$ letra a, exige-se, basicamente, que o candidato demonstre ser um leitor capaz de mostrar sua capacidade de apreender a idéia-núcleo do texto apresentado. Já para responder corretamente a solicitação b, o candidato precisa saber o que é enredo e ponto de vista, quer dizer, exige-se que o vestibulando tenha certo domínio de uma nomenclatura específica para que tenha condições de responder a contento o que é solicitado.

Segundo o centro de seleção, as respostas esperadas, utilizadas como referências para a correção dessa questão, eram:

a) De acordo com o resenhista, a obra dos irmãos Coen está acima da média da produção americana por apresentar um ponto de vista crítico com relação aos usos e costumes americanos.

0 recurso empregado pelo resenhista para exemplificar a sua opinião é a citação de outros filmes dos cineastas e sua classificação em dois 
gêneros: o humor negro (Fargo) e a comédia escrachada (Arizona nunca amais), por exemplo.

b) De acordo com a resenha, em termos de enredo, o filme é caracterizado pelo conflito entre um advogado especializado em divórcios e processos afins e uma mulher deslumbrante que busca enriquecer por meio de casamentos.

Em termos de ponto de vista, o filme é uma comédia escrachada e uma crítica à obsessão americana com advogados, processos judiciais e julgamentos.

Na página 2, são apresentadas as questões 3 e 4 . A questão 3 foi elaborada a partir de uma charge de Angeli, publicada na Folha de São Paulo no dia 13 de outubro de 2003. Nela, o comentário consiste: numa seqüência injuntiva que orienta o leitor para que "leia" uma charge apresentada; na própria charge, seguida da referência com a indicação do nome de seu autor, do local e data de publicação e na orientação com relação à leitura a ser feita, segundo a qual a charge dramatiza o problema do desemprego no Brasil. Em seguida, vem a solicitação, com perguntas a e b. Tanto em uma como em outra, o vestibulando é orientado a analisar "a combinação da linguagem verbal com a nãoverbal".

Na pergunta a, pede-se que o candidato explique "por que a situação retratada é irônica". Assim, apesar de se orientar o aluno para que "leia", o que, sob o nosso ponto de vista, significaria que o vestibulando é uma das instâncias que contribui para a constituição do sentido, é dado o pressuposto de que a situação retratada é irônica, cabendo ao candidato apenas explicar o porquê disso acontecer.

Quanto à pergunta $b$, solicita-se que 0 candidato reescreva a fala das personagens da charge, explicitando a relação entre as orações através do uso de uma conjunção ou de uma locução equivalente, sem que seja alterada a ordem das orações. De novo, o candidato deve demonstrar o domínio de uma nomenclatura gramatical: para responder a questão, tem que saber o quê e quais são as conjunções e as locuções. Além disso, também nessa questão, trabalha-se com a idéia do sentido literal, imanente ao texto, ao se dar a instrução de que o candidato deve manter "o sentido original da frase", o que vai de encontro à concepção de linguagem como forma de interação e à tese de que os sentidos são produzidos e compreendidos pelos interlocutores no processo de interação.

Segundo o centro de seleção da UFG, as respostas esperadas para a questão 4 seriam: 
a) A situação retratada é irônica porque a personagem que anuncia vagas acaba de perder seu trabalho, que é uma espécie de subemprego. A situação, por ser exagerada, chama a atenção para a gravidade do desemprego.

OU

A situação retratada é irônica porque mostra que até o trabalhador que anuncia empregos acabou de tornar-se mais um desempregado. OU

A situação retratada é irônica porque quem foi despedido tinha como profissão anunciar empregos. Se até quem anuncia empregos é despedido, então não há muito o que anunciar.

b) A resposta que mantém o sentido da frase deve conter:

Uso da conjunção ou de locução equivalente;

M anutenção do aspecto verbal;

Uso do verbo no modo subjuntivo ou na forma nominal infinitiva.

Possibilidades de construção (alguns exemplos):

- Você não vai acreditar, mas acabo de ser despedido!

- Você não vai acreditar, porém acabo de ser despedido!

- Ainda que você não acredite, acabo de ser despedido!

- Por incrível que lhe pareça, acabo de ser despedido!

- Embora você não acredite, acabo de ser despedido!

- Apesar de você não acreditar, acabo de ser despedido!

- Mesmo que você não acredite, acabo de ser despedido!

- Por mais que você não acredite, acabo de ser despedido!

Na questão 4, apresenta-se o comentário: com uma instrução para que se leia um trecho de uma matéria publicada na Folha de São Paulo no dia 26 de agosto de 2003, intitulada "Unesco reúne grupo para salvar línguas", com a indicação do local e da data da publicação. Depois disso, são feitas as perguntas a e b.

No item a, partindo do pressuposto de que "línguas mortas" é uma metáfora, pede-se que o candidato explique "como se forma o sentido metafórico" dessa expressão. Para isso, o vestibulando precisa saber o que é uma metáfora ou "o sentido metafórico". Outra vez, espera-se do vestibulando um saber metalingüístico em nível terminológico. A resposta esperada pela banca para a pergunta era mais ou menos a seguinte, segundo divulgou o Centro de Seleção: 
a) O sentido metafórico da expressão "línguas mortas" forma-se com base na comparação entre línguas e seres vivos; nesse sentido, 0 termo apresenta características similares a um organismo vivo enquanto é falada por uma comunidade. Se essa língua deixa de ser usada, torna-se morta.

Já a pergunta b é uma questão que, seguramente, pode avaliar a capacidade do candidato no que se refere à leitura. 0 candidato acertaria 0 item b da questão, conforme divulgou o centro de seleção da UFG, caso sua resposta expressasse o eixo da seguinte resposta esperada:

b) Elementos que devem compor possíveis respostas:

Estabelecimento da analogia com espécie animal;

Reconhecimento da valorização da diversidade lingüística;

Reconhecimento da língua como veículo de cultura/ identidade étnica;

Reconhecimento da língua como experiência humana/ identidade comunitária.

Possibilidade de construção da resposta:

De acordo com Grinevald, a extinção de uma língua é análoga ao desaparecimento de uma espécie animal. Como a preservação das espécies animais é uma defesa da diversidade genética (ecossistema global), há nesse raciocínio uma valorização implícita da diversidade lingüística e, por conseqüência, da diversidade sociocultural: identitária e comunitária.

\section{CONSIDERAÇÕES FINAIS}

Feita a leitura de cada questão em particular, queremos, nesse momento, fazer algumas considerações quanto a regularidades que a comparação entre elas deixa entrever, mesmo tendo consciência de que o corpus aqui analisado é um tanto restrito para análises mais consistentes e conclusões melhor acabadas.

Considerar as provas discursivas de língua portuguesa como um gênero, ou, ao menos, um sub-gênero --- é bastante provável que as provas discursivas de outras áreas também possam ser englobadas em um mesmo gênero ---, nos 
dá a possibilidade de arriscar a dizer algo sobre seu estilo, seu conteúdo temático e sua estrutura composicional.

Para começar, pensemos sobre seu conteúdo temático que, apesar de não ser 0 assunto específico de um texto, pode ser entendido como um domínio de sentido de que um gênero se ocupa, com estreita vinculação com outros gêneros pertencentes à mesma esfera de atividade. Considerando as questões discursivas de língua portuguesa como um gênero do discurso pedagógico que se vincula ao ensino como esfera de atividade, podemos supor que existam tantos outros gêneros pertencentes a esse setor que compartilham com as questões discursivas praticamente o mesmo domínio de sentido.

Analisando as quatro questões da prova discursiva de Língua Portuguesa do Processo Seletivo 2004, podemos afirmar que elas funcionam como um espaço privilegiado para a emergência de discursos que objetivam comentar, descrever e analisar a língua, o que também ocorre com outros gêneros desse mesmo setor de atividade. Para exemplificar, basta lembrarmos da primeira questão, em que, no comentário, há uma nota cujo tema é a impropriedade vocabular em textos oficiais e da quarta, que traz no comentário um texto sobre a extinção das línguas em comparação ao desaparecimento de espécies animais.

Ainda com relação ao conteúdo temático, devido à estreita relação do gênero prova discursiva de língua portuguesa com gêneros em que se divulgam as pesquisas realizadas pela lingüística, gêneros estes que fazem parte do cotidiano dos professores que compõem a banca, há, em nossa opinião, um uso excessivo de termos técnicos provenientes dos estudos gramaticais e/ou lingüísticos e literários, os quais, muitas vezes, acabam por se tornar empeciIhos para a realização de uma boa leitura por parte de muitos candidatos. Nas questões que analisamos observamos termos como enredo, ponto de vista, conjunção, locução, sentido metafórico, os quais, a despeito de denunciarem a presença da heterogeneidade constitutiva, pois remetem aos discursos da gramática, da lingüística e da teoria literária, não fazem parte das enciclopédias de certos candidatos, acabando por levá-los a leituras equivocadas das questões. Há quem defenda o ensino da teoria gramatical no ensino fundamental e médio, de nossa parte, concordamos integralmente com Possenti (2001) quando afirma que não é preciso ensinar ao aluno

o que é um anafórico, ou um precedente, ou pressuposto, ou pronome etc. Não é preciso dizer nada disso para uma pessoa ler. Se disser, não prejudica. Agora, se os professores gastarem muitas aulas para ensinar isso, seus alunos não estarão lendo e ficam prejudicados (POSSENTI, 2001, p. 6). 
Vale ressaltar que o que o Centro de Seleção propõe, teoricamente, através dos manuais de candidato, não se efetiva completamente na prática, no momento dos vestibulandos lerem as questões da prova discursiva de língua portuguesa, pois, em relação à gramática, a UFG advoga a tese de que seu estudo deve ser visto como uma "uma estratégia para compreensão/interpretação/produção de textos" (UNIVERSIDADE FEDERAL DE GOIÁS, 2004, p. 27).

Outro ponto que nos chamou a atenção foi que, contradizendo o que se propõe no manual de candidato 2004, nos quais se afirma que a leitura não é uma tarefa mecânica de decodificação, mas um processo ativo de construção de sentidos, na questão 3 do Processo Seletivo 2004, pede-se que o candidato "mantenha o sentido original da frase", o que nos leva à constatação de que ao menos nesse momento, em grande medida em razão da necessidade de cerceamento das possibilidades de leitura --- o que possibilita a correção das questões --- e por se dar o processo interativo num quadro institucional que restringe a enunciação, mantém-se uma concepção de leitura, segundo a qual há um sentido original inscrito pelo autor no texto, o que depõe contra as mais recentes abordagens sobre a leitura.

No que diz respeito à construção composicional das questões, ao "modo de organizar o texto, de estruturá-lo" (FIORIN, 2006, p. 62), destacamos que, ao contrário do que a afirmação de Chociay (1998) levaria a supor, a forma de composição das questões, constituídas de comentário e solicitação nem sempre contribui para que o candidato às vagas da UFG possa exercer sua capacidade de observação, análise e interpretação sem maiores entraves (CHOCIAY, 1998, p. 63). Como pudemos verificar, há comentários, por exemplo, que, em vez de orientar os alunos em relação ao que significa determinado termo da Lingüística ou da Teoria Literária, de cujo entendimento depende a elaboração da resposta, tratam de questões secundárias, na medida em que não contribuem diretamente para que os vestibulandos tenham condições favoráveis para elaborar suas respostas.

De qualquer modo, de fato, constatamos haver, ao menos nas questões que analisamos, essa forma de composição da questão discursiva, dividida em comentário e solicitação. Nos comentários de todas as questões, um gênero de outra esfera de atividade foi trazido para seu interior, contribuindo para a caracterização do novo gênero. Assim, nas questões aparecem charges, nota, resenha, os quais saem, em especial, da esfera jornalística para a esfera do ensino, fazendo com que os textos passem "de um gênero para outro", em razão de estar "colocado em outro contexto, ou seja, em outra esfera de atividade" (FIORIN, 2006, p. 72), além do que a mudança de suporte contribui para 
a passagem de um gênero a outro. Evidencia-se, assim, a presença bastante forte da heterogeneidade mostrada, especialmente a marcada. Talvez porque a UFG defenda, como propõe no manual do candidato do processo seletivo para ingresso em 2004, que os textos escolhidos para a elaboração das provas sejam variados, pertencendo a gêneros diversos, com as mais diferentes funções, todas as questões analisadas trazem como parte do comentário textos diversos de gêneros variados (UNIVERSIDADE FEDERAL DE GOIÁS, 2004).

Conforme expõe Marcuschi (2002b, p. 5), na composição dos gêneros entram seqüências estruturais sistemáticas a que ele denomina tipos textuais, os quais abrangem algumas poucas categorias conhecidas: a narração, a argumentação, a exposição, a descrição e a injunção. Tidos como tipologicamente heterogêneos, os gêneros podem se constituir da combinação de diversos tipos, nas mais variadas ordens. Como não poderia ser diferente, isso ocorre com o gênero em análise. Porém, queremos ressaltar a importância que a seqüência tipológica injuntiva adquire nesse gênero, na medida em que "com a seqüência injuntiva, 0 agente-produtor tem como objetivo fazer agir o destinatário e não só fazer ver" (SOUSA, 2002, p. 162). Assim, nas questões analisadas, aparecem, com certa freqüência, verbos no imperativo: leia, explique, reescreva, responda, mantenha e os pronomes interrogativos qual, como e por que.

Os verbos e os pronomes citados acima contribuem para compor o estilo desse gênero, pois, como define Fiorin (2006, p. 62), o estilo é uma "uma seleção de certos meios lexicais, fraseológicos e gramaticais em função da imagem do interlocutor e de como se presume sua compreensão responsiva ativa do enunciado".

Assim, realizadas essas análises, parece-nos que a banca construiu uma imagem dos vestibulandos como indivíduos sobre os quais ela possui um poder dado pela sua posição sócio-histórica, cabendo-lhe solicitar, deles, um conhecimento teórico-terminológico e temático bastante apurado para refletir sobre a língua e analisá-la.

\section{REFERÊNCIAS}

BAKHTIN, M. Estética da criação verbal. São Paulo: M artins Fontes, 2000.

BRASIL, Secretaria de educação fundamental. Parâmetros curriculares nacionais: língua portuguesa. Brasília: MEC/SEF, 1997.

CHOCIAY, R. Língua portuguesa no vestibular da UNESP: das perguntas às respostas. São Paulo: Imprensa Oficial, 1998.

FIORIN, J. L. Introdução ao pensamento de Bakhtin. São Paulo: Ática, 2006.

GERALDI, J. W. Portos de passagem. São Paulo: M artins Fontes, 1993. 
M ARCUSCHI, L. A. Gêneros textuais: definição e funcionalidade. In: MARCUSCHI, L. A.; DIONÍSIO, A. P.; MACHADO, A. R.; BEZERRA, M. A. Gêneros textuais e ensino. Rio de Janeiro: Lucerna, 2002a.

MARCUSCHI, L. A. Gêneros textuais e ensino de língua. Pernambuco: Universidade Federal e Pernambuco, 2002b. Mimeografado.

M ARCUSCHI, L. A. A questão do suporte dos gêneros textuais. Pernambuco: Universidade Federal e Pernambuco, 2003. Mimeografado.

PÊCHEUX, M. Análise automática do discurso. In: GADET, F.; HAK, T. (Org.). Por uma análise automática do discurso: uma introdução à obra de Michel Pêcheux. Campinas: Ed. UNICAMP, 1993.

POSSENTI, S. Existe a leitura errada? Entrevista concedida a CARVALHO, J. M. T. de; MARINHO, M. Presença Pedagógica, v. 7, n. 40, p. 5-18, 2001.

ROCCO, M. T. F. 0 vestibular e a prova de redação. Estudos em Avaliação Educacional, São Paulo, n. 11, p. 23-39, jan./jun. 1995.

RODRIGUES, R. H. 0 artigo jornalístico e o ensino da produção escrita. In: ROJO, R. (Org.). A prática de linguagem em sala de aula: praticando os PCNs. São Paulo: EDUC; Campinas: Mercado de Letras, 2002.

SOUSA, K. M. de. A redação no vestibular: textos que realizam gêneros ou tipologias? 2002. 215 f. Tese (Doutorado em Lingüística e Língua Portuguesa)-Faculdade de Ciências e Letras, Universidade Estadual Paulista, Araraquara, 2002.

UNIVERSIDADE FEDERAL DE GOIÁS. Centro de seleção. Manual do candidato: processo seletivo. 2004. Goiânia, 2004. 


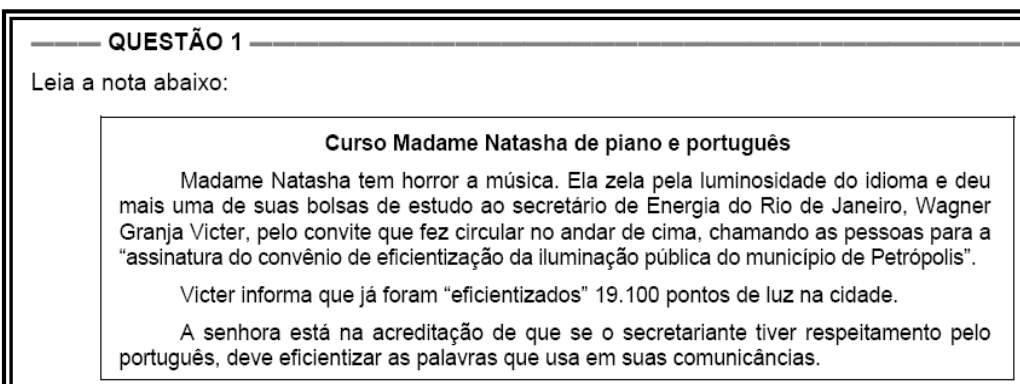

GASPARI, Elio. Folha de S. Paulo. São Paulo, 16 nov. 2003, p. A10.

Madame Natasha é uma personagem criada por Elio Gaspari com a finalidade de ridicularizar a linguagem usada por autoridades da vida pública brasileira, que, segundo o jornalista, atropelam a comunicação.

a) Analisando o trecho citado, explique por que o emprego dos termos "eficientização" e "eficientizados" está sendo criticado.

( 2,5 pontos)

b) O jornalista encerra o seu texto com uma redação sarcástica, apropriada ao contexto de sua crítica. Reescreva o último parágrafo de acordo com a norma padrão, substituindo as palavras inadequadas a esse nível de linguagem por outras de mesmo sentido, com as adaptações necessárias.

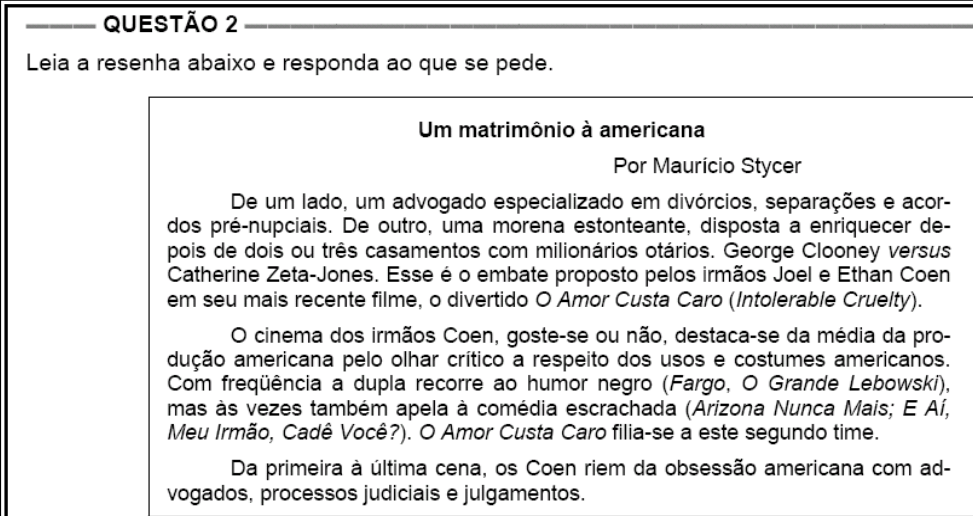

CARTA CAPITAL. São Paulo, 15 out. 2003, p. 72. [Adaptado]

a) Qual é a opinião do resenhista sobre a qualidade da produção cinematográfica dos irmãos Coen e de que recurso ele se vale para exemplificá-la?

( 2,5 pontos)

b) De acordo com a resenha, como o filme O Amor Custa Caro é caracterizado em termos de enredo e ponto de vista? www.cs.ufg.br. 
QUESTÃO 3

Leia a charge abaixo:

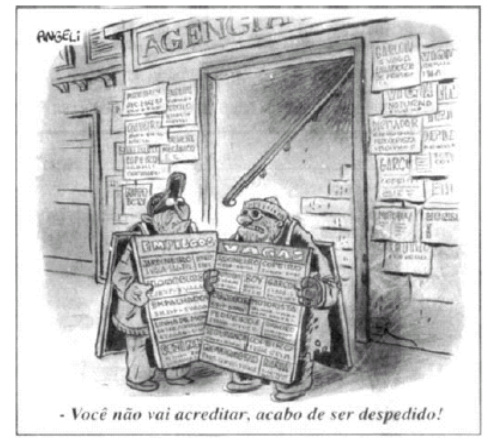

ANGELI. Folha de S. Paulo. São Paulo, 13 out. 2003, p. 2.

A charge dramatiza um grave problema social no Brasil: o do desemprego. Analisando a combinação da linguagem verbal com a não-verbal, explique:

a) Por que a situação retratada é irônica?

(3,5 pontos)

b) Reescreva a fala "Você não vai acreditar, acabo de ser despedido!", explicitando a relação entre as orações por meio de uma conjunção ou de uma locução equivalente. Mantenha o sentido original da frase e a ordem das orações.

(1,5 ponto)

- Q QUESTÃO 4

Leia o texto abaixo:

Unesco reúne grupo para salvar línguas

Fernando Eichenberg

O mundo está testemunhando a extinção não só de espécies animais: especialistas estimam que, até o final do século 21 , cerca de $90 \%$ das línguas desaparecerão. Para que, no futuro, a lingüistica não se resuma ao estudo das línguas mortas, a Unesco reuniu um grupo de experts para elaborar um plano de salvamento.

"A situação é alarmante e muito mais grave que o caso dos animais. Mas os biólogos sabem ser muito mais eficazes. Não conseguimos fazer as pessoas chorarem pela morte das línguas indígenas, por exemplo", desabafa à Folha a francesa Colette Grinevald.

FOLHA DE S. PAULO. São Paulo, 26 ago. 2003, p. 16. [Sinapse]

a) Explique como se forma o sentido metafórico da expressão "línguas mortas".

( 2,5 pontos $)$

b) Refletindo sobre a comparação (mundo natural/cultura) de Colette Grinevald, por que uma língua deve ser preservada? 
